\title{
Porosity in ion-exchanged and acid activated clays evaluated using n-nonane pre-adsorption
}

\author{
M.M.L. Ribeiro Carrott ${ }^{\text {a, }}{ }^{*}$, I.P.P. Cansado a, P.J.M. Carrott ${ }^{\text {a }}$, P.A. Russo ${ }^{\text {a, }}{ }^{1}$, P. Castilho ${ }^{\text {b }}$, \\ C. Fernandes ${ }^{b, 2}$, C. Catrinescu ${ }^{\text {b, } 3}$, C. Breen ${ }^{c}$ \\ a Departamento de Química, Escola de Ciências e Tecnologia, Centro de Química de Évora, Instituto de Investigação e Formação Avançada, Universidade de \\ Évora, Colégio Luís António Verney, 7000-671, Évora, Portugal \\ b CQM - Centro de Química da Madeira, Universidade da Madeira, Campus Universitário da Penteada, 9020-105, Funchal, Portugal \\ ${ }^{c}$ Materials and Engineering Research Institute, Sheffield Hallam University, City Campus, Howard Street, Sheffield, S1 1WB, United Kingdom
}

\section{A R T I C L E I N F O}

\section{Article history:}

Received 30 November 2015

Received in revised form

9 June 2016

Accepted 16 June 2016

Available online 17 June 2016

\section{Keywords:}

Clays

n-Nonane pre-adsorption

Microporosity

Mesoporosity

\begin{abstract}
A B S T R A C T
The applicability of the n-nonane pre-adsorption method for characterising the porosity in clays is presented. Na-SD, a Na ${ }^{+}$-exchanged purified bentonite, and materials obtained by $\mathrm{Al}^{3+}$-exchange and acid treatments of $\mathrm{Na}-\mathrm{SD}$ and $\mathrm{SAz}-1$ were used. Nitrogen adsorption isotherms, at $-196{ }^{\circ} \mathrm{C}$, were determined before and after $\mathrm{n}$-nonane pre-adsorption on each of the samples. In all materials, n-nonane remained adsorbed in ultramicropores after outgassing at $25^{\circ} \mathrm{C}$. Outgassing at higher temperatures (50, 75 and $200{ }^{\circ} \mathrm{C}$ ) removed nonane and ultramicropores became available for nitrogen adsorption. All treatments on Na-SD led to increase in micropore volume. Larger ultramicropore and supermicropore volumes were obtained for $\mathrm{Na}-\mathrm{SD}$ acid activated with $\mathrm{HCl}$ at $95^{\circ} \mathrm{C}$ than for treatments at $25^{\circ} \mathrm{C}$ with $\mathrm{HCl}$ or following $\mathrm{Al}^{3+}$-exchange (Al-SD), and increased with increasing acid concentration to $3 \mathrm{M}$. Activation with $4 \mathrm{M} \mathrm{HCl}$ led to the largest pore volume with contribution from mesopores. However, the specific external surface area was the same as that obtained for Na-SD, Al-SD and for most of the other acid activated samples. Treatments at $95{ }^{\circ} \mathrm{C}$ with $1 \mathrm{M}$ and $6 \mathrm{M} \mathrm{HCl}$ promoted increase in specific external surface area. The micropore volumes and specific external surface area for SAz-1 treated with $1 \mathrm{M} \mathrm{HCl}$ at $95{ }^{\circ} \mathrm{C}$ were larger than those of $\mathrm{Al}-\mathrm{SAz}-1$, but lower than those obtained for corresponding materials derived from Na-SD. The n-nonane pre-adsorption method enabled micropore volumes and specific external surface areas to be obtained for all samples.
\end{abstract}

() 2016 Elsevier Inc. All rights reserved.

\section{Introduction}

The n-nonane pre-adsorption method was introduced in 1969 by Gregg and Langford for the evaluation of the microporosity present in certain carbon blacks [1]. The reasons for choosing $n-$ nonane were, on the one hand, the long chain molecules are

\footnotetext{
* Corresponding author.

E-mail address: manrc@uevora.pt (M.M.L. Ribeiro Carrott).

1 Present address. Humboldt-Universität zu Berlin, Institut für Chemie, Berlin, Germany (P. A. Russo).

2 Present address. Laboratório Regional de Engenharia Civil (Madeira), Departamento de Estruturas, Materiais de Construção e Vias de Comunicação, 9000-264 Funchal, Portugal (C. Fernandes).

3 Present address. "Gheorghe Asachi" Technical University of Iasi, Department of Environmental Engineering and Management, 700050 Iasi, Romania (C. Catrinescu).
}

strongly adsorbed in narrow pores and remain there upon outgassing at room temperature and, on the other hand, the narrow linear molecules are able to enter into narrow micropores. The original experimental procedure demonstrated the suitability of choosing n-nonane and consisted of determining the nitrogen adsorption isotherm when the micropores had been filled with nnonane and then after they had been progressively emptied by outgassing at elevated temperatures, until they were completely empty [1,2].

n-Nonane pre-adsorption has subsequently been evaluated for a variety of other materials and it has been shown that it can be applied to other types of carbon materials, including activated carbons [3-5], carbon nanotubes [6] carbon aerogels [7,8], ordered mesoporous carbon and silicon carbide [9] and also other microporous materials, including titanium dioxide [10], $\gamma-\mathrm{MnO}_{2}$ [11], ammonium phosphomolybdate, phosphotungstate and 
silicomolybdate [12], silicalite-I [13], silica-pillared layered manganese oxide [14], ordered mesoporous silicas [15] and silica spheres [16]. The results from this variety of materials have confirmed the value of using n-nonane pre-adsorption for the evaluation of microporosity and to obtain additional insight into the pore structures. To the best of our knowledge, there is not any previous article regarding application of $n$-nonane pre-adsorption to clays or materials derived from them.

Clay porosity, especially when expanding clays are dominant, is readily modified using acid activation and ion-exchange. The alterations depend on the specific treatment conditions and on the nature of the starting clays, as our previous works illustrate $[17,18]$. Complex porosity can result and, if micropores of different sizes are present together with external surface area, evaluation of the microporosity is not straightforward from nitrogen adsorption at $-196{ }^{\circ} \mathrm{C}$ alone. Pre-adsorption of n-nonane can be an effective way of isolating the micropores $[2,19,20]$.

Hence, in this work it is intended to show that n-nonane preadsorption method can be applied to clays and to obtain, using this method, a quantitative description of microporosity and specific external surface area of acid treated and ion-exchanged clays. The materials used in this study are a new set of materials resulting from acid treatment of $\mathrm{Na}-\mathrm{SD}$ with $\mathrm{HCl}$ solutions, and also some materials from previous work [18] namely Na-SD, Al-SD, Al-SAz-1 and one sample of acid activated SAz-1.

\section{Materials and methods}

\subsection{Materials preparation}

The starting raw bentonite (SD) was collected at Serra de Dentro, Porto Santo Island (Madeira Archipelago, Portugal) as in our previous works $[17,18]$. The major impurities were removed by low speed centrifugation ( $6 \mathrm{~min}$, at $600 \mathrm{rpm}$ ), to obtain the $<2 \mu \mathrm{m}$ size fraction. Carbonates were removed by addition of sodium acetate-acetic acid buffer until the clay suspension reached $\mathrm{pH}$ 6.8. Removal of organic matter was accomplished using hydrogen peroxide in acidic medium, at $90{ }^{\circ} \mathrm{C}$. Sodium dithionite-sodium citrate buffered at $\mathrm{pH}=8.3$ was used to eliminate free oxides of iron, aluminium, titanium and manganese. Then, the product was converted into the Na-exchanged form using $1 \mathrm{M}$ aqueous sodium chloride solution. Excess $\mathrm{Cl}^{-}$ was removed by dialysis and the powdered clay, labelled Na-SD, was obtained after drying the gel collected following centrifugation at $4500 \mathrm{rpm}$ for $30 \mathrm{~min}$.

SAz-1 (Cheto, Arizona, USA) is a higher charge montmorillonite obtained from The Clay Mineral Society Source Clay repository (Purdue University); it was suspended in deionized water and the $<2 \mu \mathrm{m}$ size fraction was collected by centrifugation. It was modified using two different approaches: (a) Acid activation by shaking with $1 \mathrm{M} \mathrm{HCl}$ at $95{ }^{\circ} \mathrm{C}$ for $30 \mathrm{~min}$, leading to the sample SAz195 and (b) ion exchange by shaking the original SAz- 1 with $0.3 \mathrm{M} \mathrm{Al}\left(\mathrm{NO}_{3}\right)_{3}$, for $30 \mathrm{~min}$ at room temperature. This was repeated, three times, before rigorous washing to provide $\mathrm{Al}-\mathrm{SAz}-1$. Al-SD was obtained from $\mathrm{Na}-$ SD using the same procedure.

Acid activated samples were prepared by mixing $10 \mathrm{~g}$ of $\mathrm{Na}-\mathrm{SD}$ with $300 \mathrm{~cm}^{3}$ aliquots of aqueous $\mathrm{HCl}$ at $25^{\circ} \mathrm{C}$ for $120 \mathrm{~min}$ or $95^{\circ} \mathrm{C}$ for $30 \mathrm{~min}$. The samples were then mixed with a large quantity of cold water to effectively terminate the leaching process, centrifuged and washed successively until a stable $\mathrm{pH}$ was achieved, and finally they were air-dried for $24 \mathrm{~h}$. Samples are labelled according to the acid concentration and temperature of activation. For example, SD495 is the material obtained when a $10 \mathrm{~g}$ sample of $\mathrm{Na}-$ SD was treated with $4 \mathrm{M} \mathrm{HCl}$ at $95^{\circ} \mathrm{C}$.

\subsection{Nitrogen adsorption at $-196{ }^{\circ} \mathrm{C}$ and n-nonane pre-adsorption}

Nitrogen adsorption isotherms were determined, at $-196{ }^{\circ} \mathrm{C}$, on a Quadrasorb SI from Quantachrome Instruments, using helium (for dead space calibration) and nitrogen of $99.999 \%$ purity supplied, respectively, by Linde and Air Liquid. Pre-adsorption of n-nonane was carried out in a custom made apparatus in pyrex and with $\mathrm{J}$. Young greaseless teflon taps. Nonane (>99\% purity, Sigma-Aldrich) was pretreated with $3 \mathrm{~A}$ molecular sieves and then outgassed by three solidification-melting cycles. In all cases, high vacuum was attained using vacuum systems equipped with turbomolecular pumps.

Prior to the adsorption measurements, all initial samples were outgassed for $5 \mathrm{~h}$ at $200{ }^{\circ} \mathrm{C}$, achieved using a heating rate of $1{ }^{\circ} \mathrm{C} \mathrm{min}^{-1}$. After determining the nitrogen isotherm, the sample cell was transferred to the custom made apparatus, and the sample was outgassed for $1 \mathrm{~h}$. Subsequently, n-nonane pre-adsorption was carried out as follows. The sample was left in contact with n-nonane vapour for $1 \mathrm{~h}$ at room temperature and then the sample cell was immersed in liquid nitrogen for $30 \mathrm{~min}$. Afterwards, the sample was outgassed at $-196{ }^{\circ} \mathrm{C}$ for $30 \mathrm{~min}$, then it was allowed to warm up to $25^{\circ} \mathrm{C}$ and outgassed for a further $5 \mathrm{~h}$. It was then transferred to the analysis station to determine the nitrogen isotherm. Afterwards, each sample was then outgassed at increasingly higher temperatures and nitrogen adsorption isotherms were successively determined after each stage of outgassing. Outgassing procedures were $5 \mathrm{~h}$ at 50 and $75{ }^{\circ} \mathrm{C}$, achieved using $1{ }^{\circ} \mathrm{C} \mathrm{min}^{-1}$, while for $200{ }^{\circ} \mathrm{C}$ the temperature programme was $2{ }^{\circ} \mathrm{C} \mathrm{min}^{-1}$ up to $100{ }^{\circ} \mathrm{C}$, then to $150^{\circ} \mathrm{C}$ and finally to $200^{\circ} \mathrm{C}$, staying $1 \mathrm{~h}$ at each temperature.

In all cases, the sample cell was filled with nitrogen $(99.999 \%$ purity) before transferring it to and from the Quadrasorb analysis station, where the sample was again outgassed for a further $1 \mathrm{~h}$ before determining the nitrogen adsorption isotherm. In order to eliminate differences in amounts adsorbed due to the changes in mass of n-nonane, the amounts of nitrogen adsorbed are all expressed per $g$ of the corresponding initial sample outgassed at $200{ }^{\circ} \mathrm{C}$, prior to n-nonane pre-adsorption.

\section{Results and discussion}

\subsection{Nitrogen isotherms and analysis by the Brunauer-Emmett- Teller (BET) method}

Nitrogen adsorption-desorption isotherms, at $-196{ }^{\circ} \mathrm{C}$, determined on Na-SD and acid treated $\mathrm{Na}-\mathrm{SD}$, before n-nonane preadsorption, are presented in Fig. 1. The isotherms were analysed by the BET method as recommended, to avoid any subjectivity in evaluating the BET monolayer capacity, following the main criteria [20], and the results are presented in Table 1. It is evident that the materials exhibit similar types of isotherm and hysteresis loop common to clays, indicating platy particles [20] even after the acid treatments up to high acid concentration. However, it is clear that the amounts adsorbed by acid treated materials are superior to those by Na-SD, indicating increase of specific surface area and/or porosity as confirmed by the BET specific surface areas, considering $0.162 \mathrm{~nm}^{2}$ for the nitrogen cross-sectional area, presented in Table 1 for the initial samples. Nitrogen isotherms of Al-SD, Al-SAz-1 and SAz195 were previously reported [18] and results of the analysis by the BET method are included in Table 1 for Al-SD and in Table 2 for Al-SAz-1 and SAz195. It can be seen that similar features were found with the $\mathrm{Al}^{3+}$-exchanged clay and SAz-1 treated with $1 \mathrm{M}$ $\mathrm{HCl}$ (SAz195).

The specific surface areas of Na-SD and acid treated Na-SD are smaller than those from previous work [17], which, at least partially, probably reflects variations due to sampling location or 


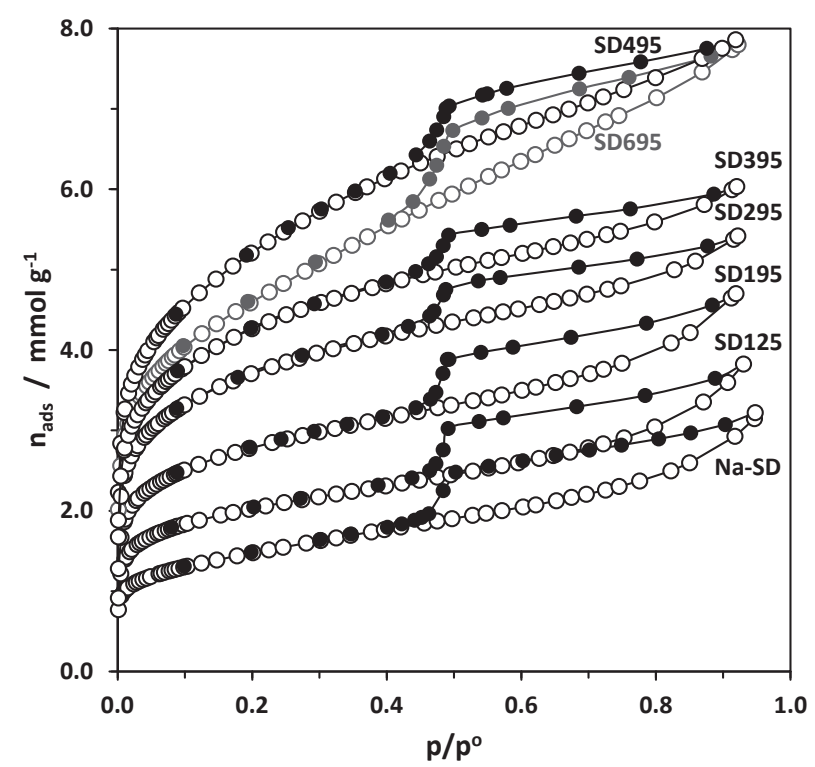

Fig. 1. Nitrogen adsorption-desorption isotherms, at $-196{ }^{\circ} \mathrm{C}$, determined on Na-SD and acid treated with $1 \mathrm{M} \mathrm{HCl}$ at $25^{\circ} \mathrm{C}(120 \mathrm{~min})$ and with $1,2,3,4$ and $6 \mathrm{M} \mathrm{HCl}$ at $95{ }^{\circ} \mathrm{C}(30 \mathrm{~min})$.

aging in the extensive deposit. Increase in specific surface area is observed following acid treatment and it is more accentuated at higher temperature, albeit for shorter time, as can be seen by comparing SD195 with SD125. Additionally, in all isotherms the adsorption is high at low relative pressures which, together with the relatively high $C$ values ( $>150$ ) observed for all initial samples, strongly suggests that all samples have narrow micropores that fill by primary micropore filling [2], that is ultramicropores, and therefore the values of BET-area should be considered as apparent surface areas $[2,21]$. It is clear that using the BET method to analyse the nitrogen adsorption isotherms of the initial samples is not sufficient for detailed characterisation.

Consequently, n-nonane pre-adsorption was performed. Nitrogen adsorption isotherms determined at $-196{ }^{\circ} \mathrm{C}$ on some initial samples and after n-nonane adsorption followed by outgassing at several temperatures are shown in Fig. 2. The results of the analysis by the BET method of the nitrogen adsorption isotherms obtained, also as recommended [20], for all samples of the SD series are presented in Table 1.

It is evident in Fig. 2 that n-nonane is retained after outgassing at $25^{\circ} \mathrm{C}$. With increasing outgassing temperature the n-nonane is progressively removed and after the final outgassing procedure the nitrogen adsorption isotherm for each sample coincides with the corresponding initial isotherm. Similar results were obtained for the other acid treated samples and also for $\mathrm{Al}^{3+}$-exchanged samples. It can be seen in Table 1 that, for all samples of the SD series after n-nonane adsorption with subsequent outgassing at $25^{\circ} \mathrm{C}$, not only the specific surface area but also the $\mathrm{C}$ values are reduced, confirming that n-nonane remains adsorbed after outgassing at $25^{\circ} \mathrm{C}$. Although retention on external surface cannot be excluded solely from this analysis, it indicates that ultramicroporosity is no longer accessible to nitrogen at $-196{ }^{\circ} \mathrm{C}$. This can be due to filling of narrow micropores with n-nonane or even to blockage of micropores by n-nonane molecules adsorbed at their entrances. Furthermore, it can be seen in Table 1 that the specific surface areas are practically restored after desorbing nnonane at $75{ }^{\circ} \mathrm{C}$ for SD695 and at $200{ }^{\circ} \mathrm{C}$ for all the other samples.

In order to determine whether n-nonane pre-adsorption could be used with other montmorillonites, the same method was also

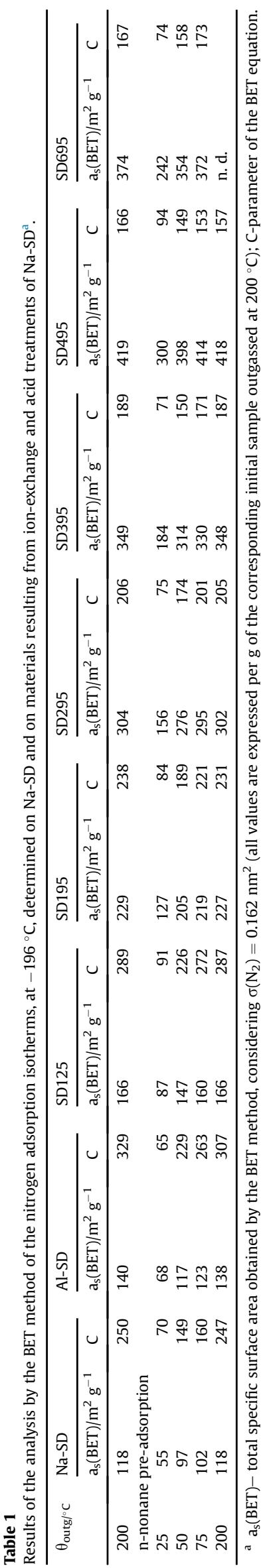


Table 2

Results of the analysis by the BET method of the nitrogen adsorption isotherms, at $-196^{\circ} \mathrm{C}$, determined on materials resulting from ion-exchange and acid treatments of SAz- $1^{\mathrm{a}}$.

\begin{tabular}{|c|c|c|c|c|}
\hline \multirow[t]{2}{*}{$\theta_{\text {outg } /{ }^{\circ} \mathrm{C}}$} & \multicolumn{2}{|l|}{ Al-SAz-1 } & \multicolumn{2}{|l|}{ SAz195 } \\
\hline & $\mathrm{a}_{\mathrm{s}}(\mathrm{BET}) / \mathrm{m}^{2} \mathrm{~g}^{-1}$ & C & $\mathrm{a}_{\mathrm{s}}(\mathrm{BET}) / \mathrm{m}^{2} \mathrm{~g}^{-1}$ & $\mathrm{C}$ \\
\hline 200 & 96 & 490 & 169 & 288 \\
\hline \multicolumn{5}{|c|}{ n-nonane pre-adsorption } \\
\hline 25 & 32 & 48 & 75 & 64 \\
\hline 50 & 75 & 249 & 144 & 194 \\
\hline 75 & 86 & 379 & 157 & 241 \\
\hline 200 & 93 & 485 & 167 & 294 \\
\hline
\end{tabular}

${ }^{\mathrm{a}} \mathrm{a}_{\mathrm{s}}$ (BET) - total specific surface area obtained by the BET method, considering $\sigma\left(\mathrm{N}_{2}\right)=0.162 \mathrm{~nm}^{2}$ (all values are expressed per $\mathrm{g}$ of the corresponding initial sample outgassed at $\left.200{ }^{\circ} \mathrm{C}\right) ; \mathrm{C}$ - parameter of the BET equation.

applied to Al-SAz-1 and SAz195, and qualitatively similar results were obtained as can be seen in Table 2, confirming that n-nonane pre-adsorption does not damage the samples.

Although the results of n-nonane pre-adsorption obtained with all samples show similar tendencies, there are differences in the detail, as can be seen, for example, in Fig. 2(a) and (b). For Na-SD the isotherms determined after outgassing at 50 and $75{ }^{\circ} \mathrm{C}$ are closer than those determined after outgassing at 75 and $200^{\circ} \mathrm{C}$, while the opposite is observed for those determined on SD125. This observation suggests the presence in Na-SD of a larger amount of narrow micropores or narrow entrances, on which n-nonane is more strongly adsorbed and is corroborated by the results presented in Table 1 for these samples. In fact, it can be seen that, after outgassing above $75^{\circ} \mathrm{C}$, there is a larger increase in BET specific area and $\mathrm{C}$ for Na-SD than for SD125. In order to obtain more detailed information the results of the n-nonane pre-adsorption method were analysed by the $\alpha_{\mathrm{S}}$ method.

\subsection{Analysis by the $\alpha_{S}$ method}

\subsubsection{General analysis of the $\alpha_{S}$ plots}

Normally, in empirical methods for isotherm analysis (such as $\alpha_{S}$ or $t$ methods), reference data for adsorption obtained on nonporous material, chemically similar to the materials under study, is used to construct the $\alpha_{S}$ or t plots. For the materials under analysis the ideal reference should be a non-porous montmorillonite but published data does not exist. Analysis of the nitrogen adsorption isotherms obtained in the samples, using published reference nitrogen adsorption data on different materials, resulted in $\alpha_{S}$ or t plots with short and/or not well defined linear sections and the interpretation of the plots was not straightforward. Consequently, for analyzing the nitrogen adsorption data it was found more appropriate to use as reference the nitrogen adsorption isotherm determined on one of the materials.

It is noted that, for each sample, the nitrogen adsorption isotherms appear to be parallel in the multilayer region, which means that the vertical displacements may only be due to removal of $n$ nonane from micropores. In this sense, the nitrogen adsorption isotherm of material with pre-adsorbed n-nonane after outgassing at $25{ }^{\circ} \mathrm{C}$ is a possibility for each sample. However, if one of these isotherms is chosen to analyse the nitrogen adsorption isotherms of all samples, it additionally allows comparing between samples the corresponding isotherm with n-nonane pre-adsorbed after outgassing at $25{ }^{\circ} \mathrm{C}$. For this work, it is reasonable to choose the adsorption isotherm of Na-SD with n-nonane adsorbed after outgassing at $25^{\circ} \mathrm{C}$ (designated by Na-SD_C9(25) in the following text) as a reference isotherm to obtain the $\alpha_{S}$ plots. As previously noted in section 3.1 such material with pre-adsorbed n-nonane can be considered as a material without ultramicropores since they are not available to nitrogen adsorption at $-196^{\circ} \mathrm{C}$.

The nitrogen adsorption isotherm of Na-SD_C9(25), was fitted with polynomials encompassing several relative pressure ranges with relevant overlap. Following, the equations were reduced to the $\alpha_{S}$ form and the method was applied as usual to construct the $\alpha_{S}$ plots $[2,20]$. In Fig. 3 the $\alpha_{S}$ plots corresponding to the nitrogen adsorption isotherms of Na-SD, Al-SD and SD195 (Na-SD acid treated with $1 \mathrm{M} \mathrm{HCl}$ ), using Na-SD_C9(25) as reference material, are presented.

It should be noted that in all cases experimental data are plotted as a function of calculated $\alpha_{\mathrm{S}}$. Therefore, the fact that the plot corresponding to Na-SD_C9(25) in Fig. 3(a) is linear over the whole range of experimental data and back-extrapolates to the origin, confirms that the fit was properly done. For the other samples, with pre-adsorbed n-nonane after outgassing at $25^{\circ} \mathrm{C}$, it can be seen in Fig. 3(b), (c) and (d) that the $\alpha_{\mathrm{s}}$ plots exhibit well defined linear sections in all cases, but none extends over the entire range of experimental data, indicating differences in porosity from $\mathrm{Na}-$ SD_C9(25). For clays resulting from acid treatment with concentrations higher than $1 \mathrm{M}$ the $\alpha_{\mathrm{S}}$ plots obtained are qualitatively similar to those of SD295 and SD495 presented in Fig. 4.

The $\alpha_{S}$ plots corresponding to the nitrogen adsorption isotherms for Al-SAz-1 and SAz195, initial and after pre-adsorption of nnonane followed by outgassing at several temperatures, are presented in Fig. 5. It is evident that well defined linear sections are also obtained in the $\alpha_{S}$ plots for these samples when using NaSD_C9(25) as reference material.

Furthermore, for each sample, the solid lines are all parallel indicating that $n$-nonane is being removed from several groups of pores upon increasing outgassing temperature and that it was removed from external surfaces upon outgassing at $25^{\circ} \mathrm{C}$. Therefore, the pore capacities and adsorption on the specific surface area external to the pores can be obtained, respectively, from the intercept and slope of each straight line. In fact, for each sample, a constant value of specific external surface area was obtained for the materials with and without n-nonane pre-adsorbed. As such, the difference between the pore volumes calculated from the intercept of one line and from the intercept of the previous line, obtained after outgassing at $\mathrm{T}$ and $\mathrm{T}^{\prime}$ respectively, will correspond to the pore volume of the group of pores from which n-nonane is desorbed. The values were calculated, using as usual the normal liquid density of nitrogen at $-196{ }^{\circ} \mathrm{C}$, from all $\alpha_{\mathrm{S}}$ plots and just from the intercepts of the straight lines, without any assumption regarding the type of pores, pore volumes were obtained and are presented in Fig. 6 for all clays.

Taking into account that at $25^{\circ} \mathrm{C}$ the n-nonane is removed from pores and/or pore entrances that are wider than those from which it is removed at higher temperatures, the effects of modification treatments on Na-SD and a comparison between the several clays can be inferred from Fig. 6 .

It is clear that the treatment of $\mathrm{Na}-\mathrm{SD}$ with $\mathrm{HCl}$ solutions causes an increase in the total pore volume, which increases with the treatment temperature and as the acid concentration increases up to $4 \mathrm{M}$. Furthermore, the bars corresponding to volumes emptied by outgassing at $25{ }^{\circ} \mathrm{C}$, indicate the appearance of wider pores in all modified clays, reaching the maximum for SD495. These wider pores are responsible for the higher total pore volume of SD495, as it can be seen that the pore volume of narrower pores, from which $\mathrm{n}$-nonane is removed at $50{ }^{\circ} \mathrm{C}$ and above, is greatest for SD395. Therefore, up to a concentration of $3 \mathrm{M}$ the acid treatments cause increase of pore volumes of wide and narrow pores. When the acid concentration is $4 \mathrm{M}$ some narrow pores disappear or become wider. When the concentration is taken to $6 \mathrm{M}$ some wide pores disappear and very narrow pores disappear or become wider, in 


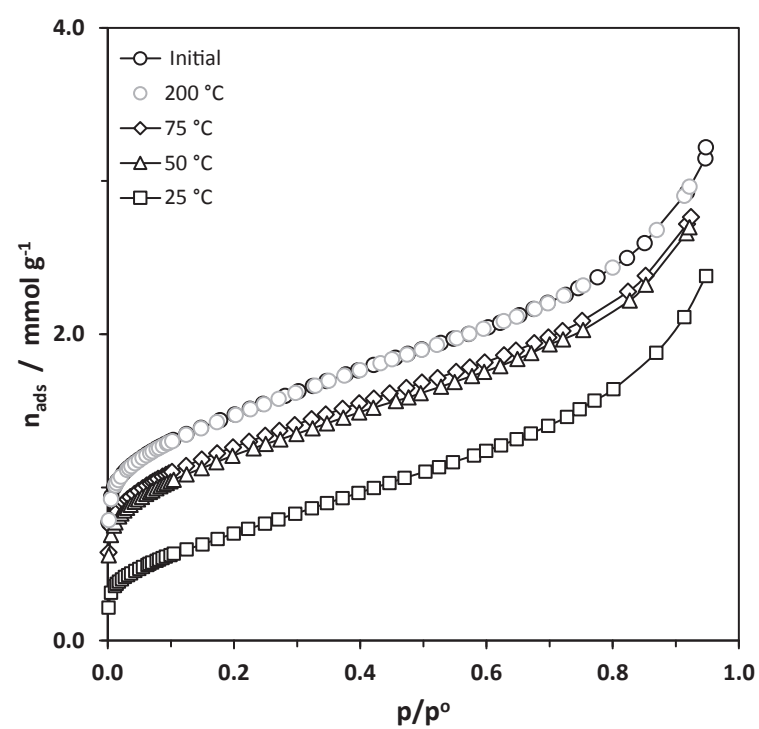

(a)

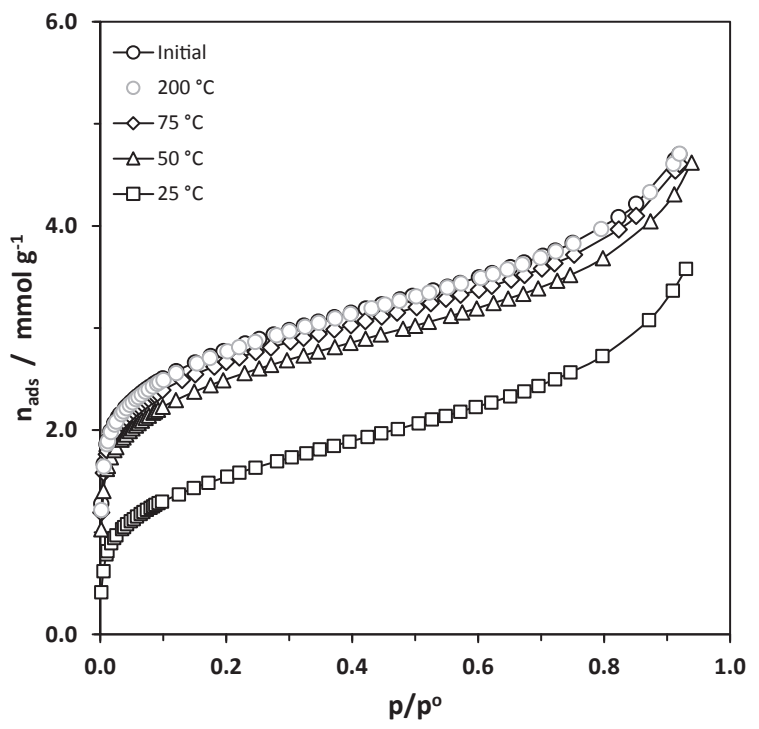

(c)

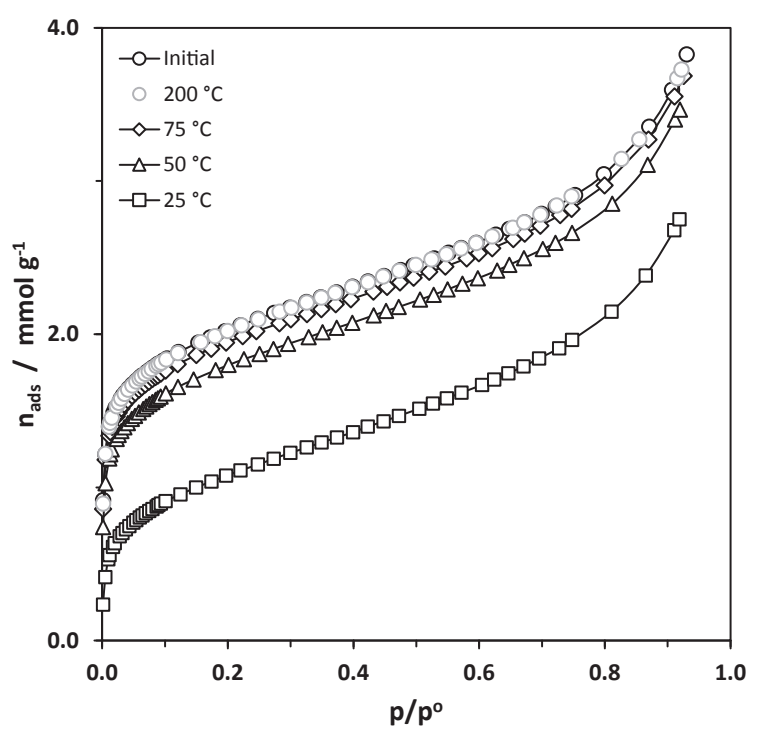

(b)

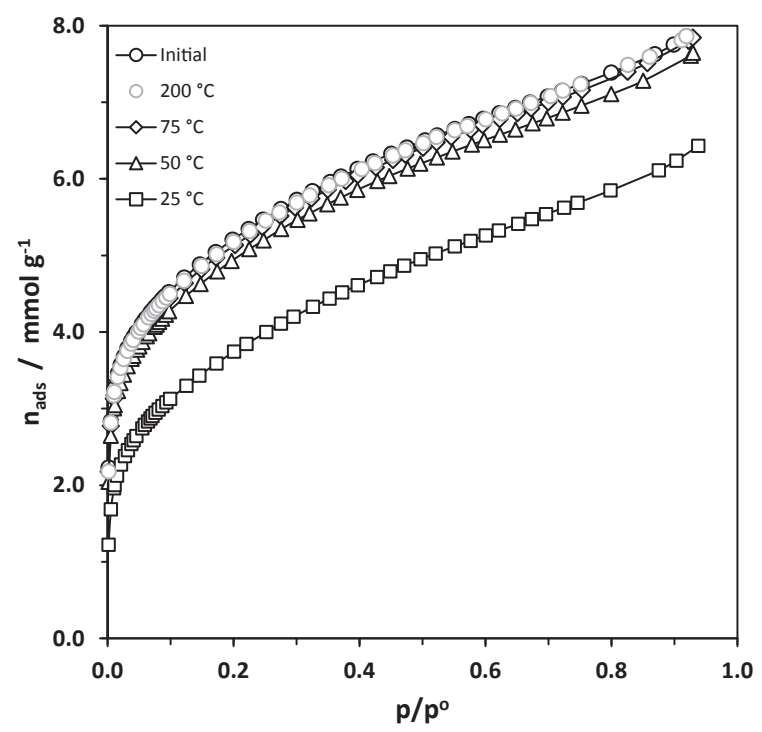

(d)

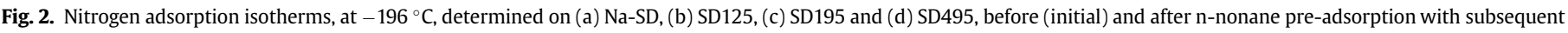
outgassing at increasing temperatures. (The amounts adsorbed are, in all cases, expressed per $\mathrm{g}$ of the corresponding initial material outgassed at $200{ }^{\circ} \mathrm{C}$ ).

spite of the observed increase in volume of narrow pores in relation to SD495.

It can be seen in Fig. 6 that the total pore volumes of Al-SAz-1 and Al-SD are not very different, with that of the latter being slightly larger. This is due to the existence of pores from which nnonane is removed at $25{ }^{\circ} \mathrm{C}$ and also a larger volume of narrower pores from which n-nonane is removed at $50{ }^{\circ} \mathrm{C}$ and above. Acid treatment of SAz-1 with $1 \mathrm{M} \mathrm{HCl}$, causes increase of wide and also of narrow pores in comparison with $\mathrm{Al}-\mathrm{SAz}-1$.

In order to complement the discussion of Fig. 6, a more detailed analysis of the $\alpha_{S}$ plots is presented in the following subsections, which makes it possible to specify the types of pores from which nnonane is desorbed at $25{ }^{\circ} \mathrm{C}$ or at $50{ }^{\circ} \mathrm{C}$ and higher temperatures.

\subsubsection{Porosity of Na-SD, Al-SD and Na-SD treated with $1 \mathrm{M} \mathrm{HCl}$}

Starting with the plots obtained for SD125 and SD195, it can be seen in Fig. 3(b) and (d) that there is, for each sample with preadsorbed n-nonane and outgassed at $25{ }^{\circ} \mathrm{C}$, a short linear section at low $\alpha_{S}$ values, that back-extrapolates to the origin. Specific surface areas calculated from the slopes of the straight lines (dashed lines) are close to the corresponding BET specific surface areas. These observations confirm that the materials with pre-adsorbed n-nonane and outgassed at $25{ }^{\circ} \mathrm{C}$ do not have ultramicropores accessible to nitrogen at $-196{ }^{\circ} \mathrm{C}$, as was inferred from the lower $\mathrm{C}$ values in Table 1. Moreover, the second linear section starts at $\alpha_{\mathrm{S}}$ values corresponding to relative pressures at which secondary micropore filling can be complete and lower to onset of 


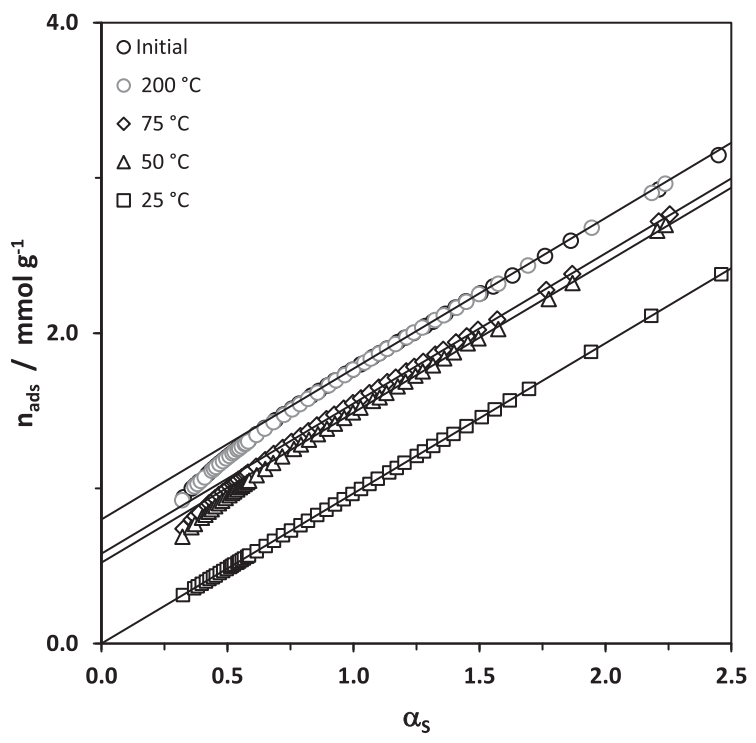

(a)

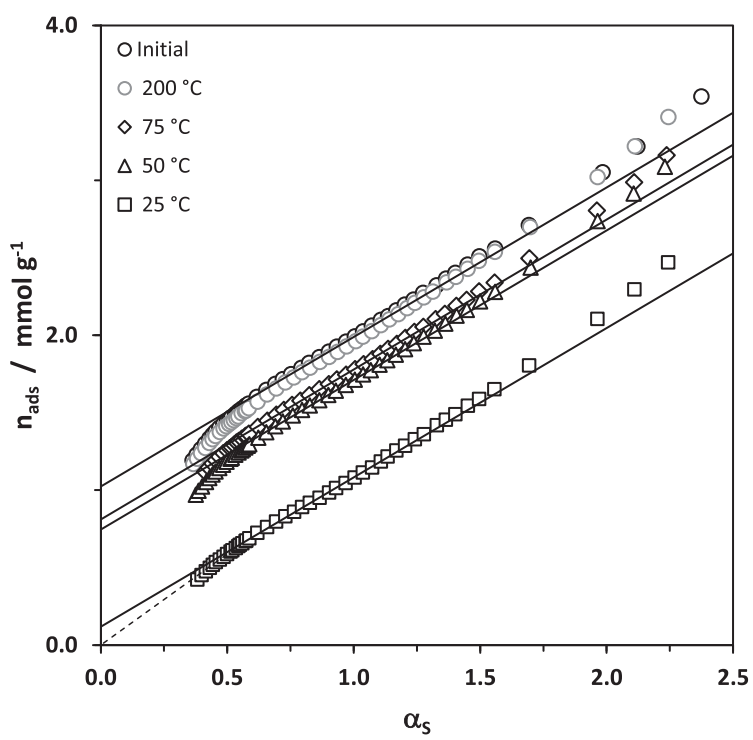

(c)

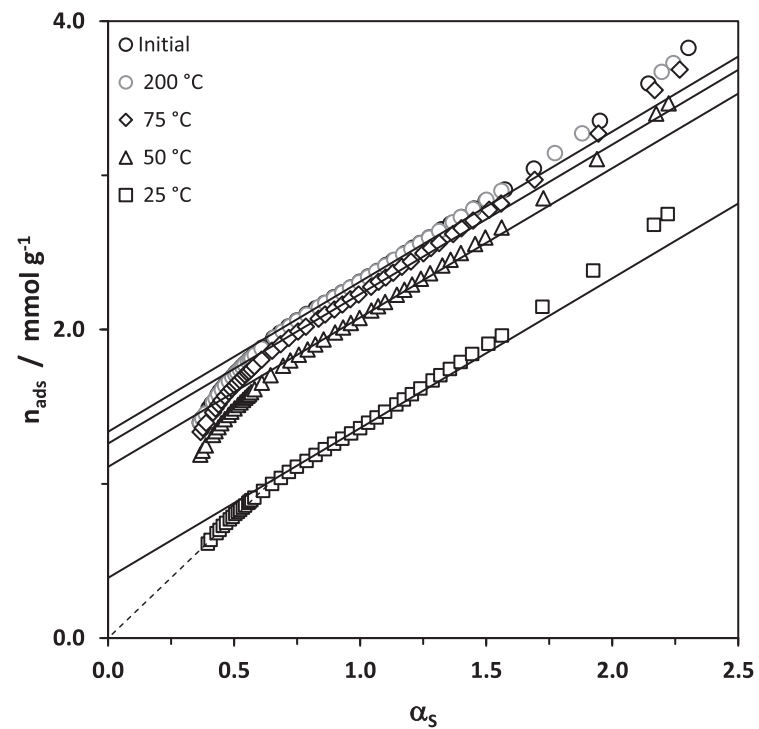

(b)

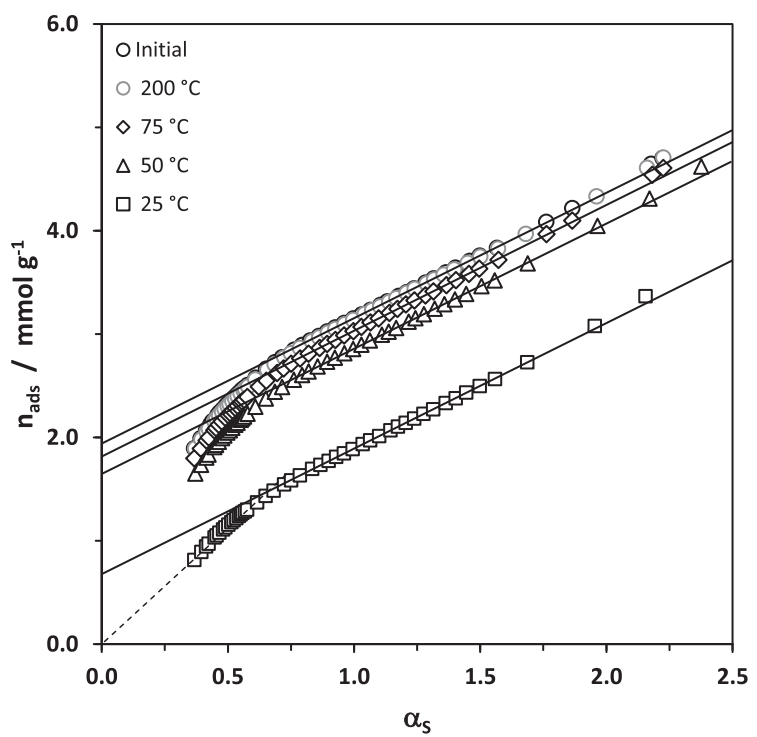

(d)

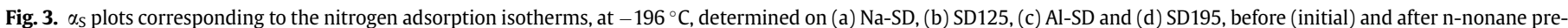

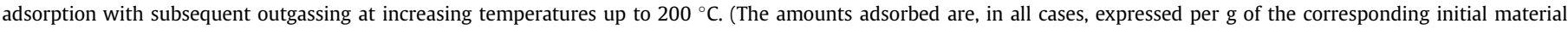
outgassed at $200{ }^{\circ} \mathrm{C}$ ).

condensation of nitrogen, at $-196{ }^{\circ} \mathrm{C}$. At $\alpha_{S}$ well above 1.0 the plots show upward deviations to the linearity indicating condensation of nitrogen, but to a greater extent when the treatment is carried out at lower temperature and longer time as the deviations are more pronounced for SD125 than for SD195.

Therefore, for each of these samples: the first linear section that back-extrapolates to the origin, corresponds to secondary micropore filling [2], that is in supermicropores [20,21], and to monomultilayer adsorption on surfaces external to these supermicropores; the second linear section corresponds to multilayer adsorption on surfaces external to supermicropores and the intercepts of the second linear sections provide values for the amounts of nitrogen adsorbed, at $-196{ }^{\circ} \mathrm{C}$, in supermicropores.

Therefore these $\alpha_{S}$ plots allow calculation of specific surface area external to the supermicropores from the slope of the second straight line (solid). The values obtained for SD125 and SD195 are, respectively, $55 \mathrm{~m}^{2} \mathrm{~g}^{-1}$ and $69 \mathrm{~m}^{2} \mathrm{~g}^{-1}$. It can be seen that the specific external surface area of SD125 is equal to the BET specific area of Na-SD_C9(25) in Table 1, while that of SD195 is larger. Thus, it can be concluded that the acid treatment with $1 \mathrm{M} \mathrm{HCl}$ at low temperature causes an increase in the volume of supermicropores without affecting the specific surface area external to the micropores, whereas the treatment at higher temperature provokes a 


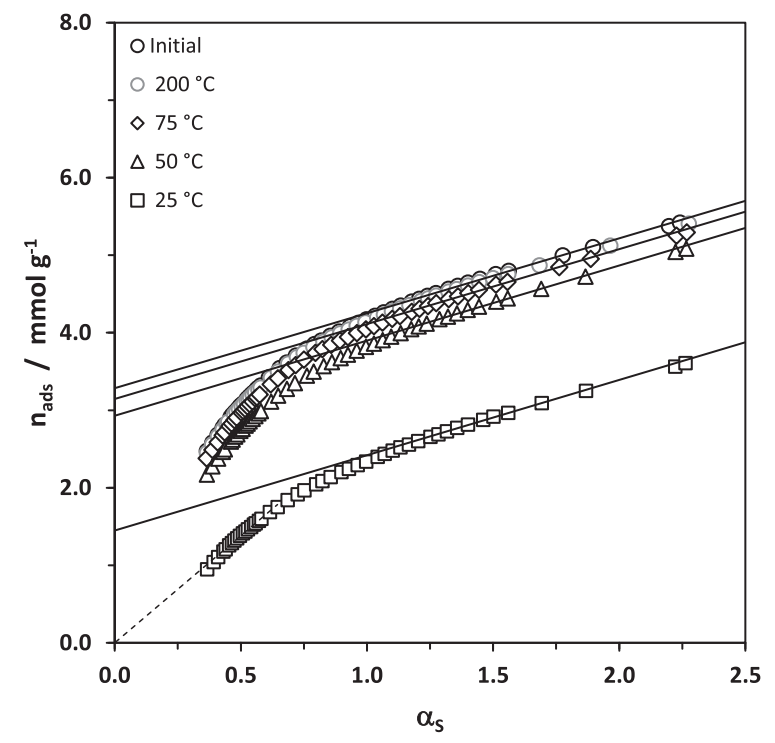

(a)

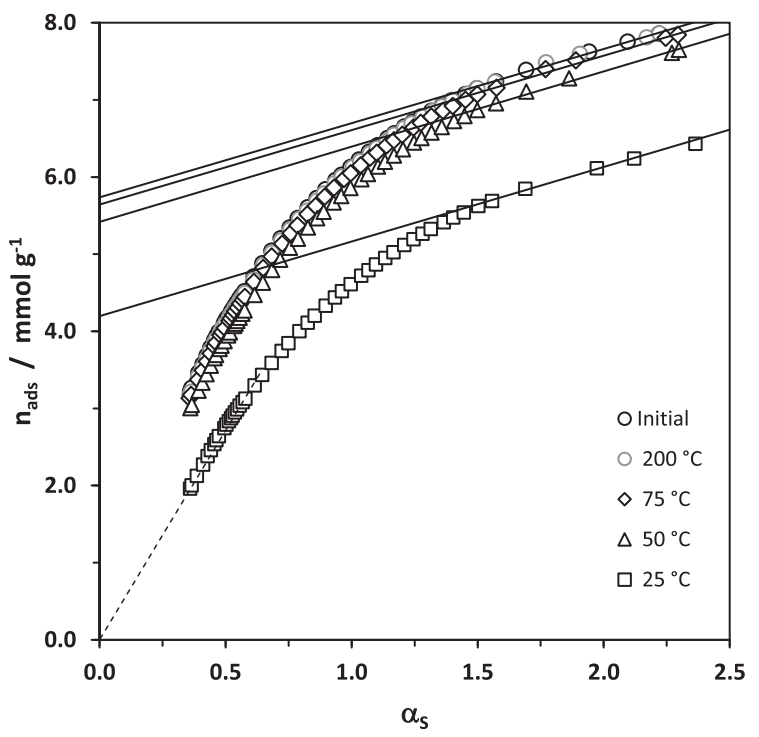

(b)

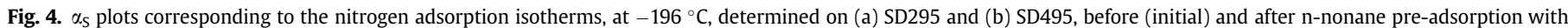

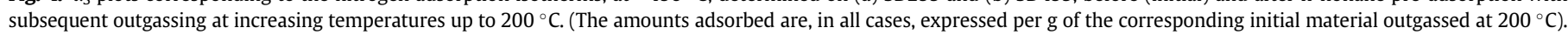

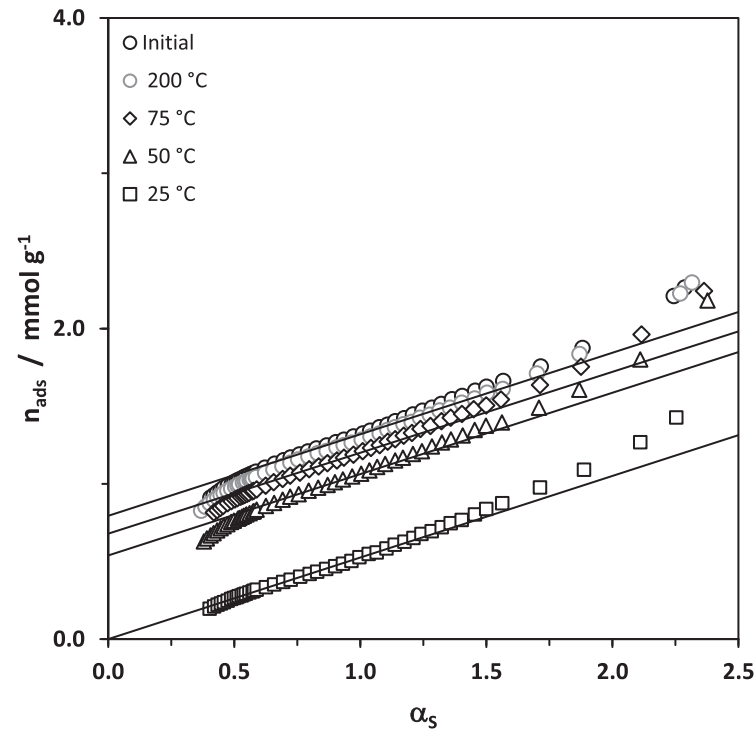

(a)

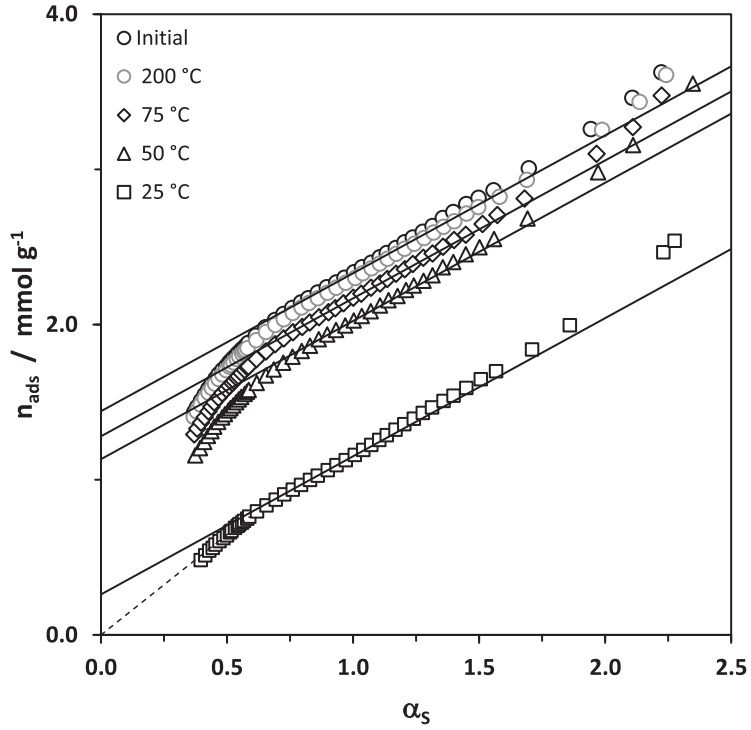

(b)

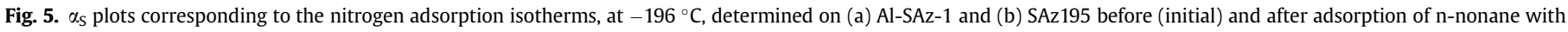
subsequent outgassing at increasing temperatures. (The amounts adsorbed are, in all cases, expressed per g of the corresponding initial material outgassed at $200{ }^{\circ} \mathrm{C}$ ).

larger increase in volume of supermicropores and additionally it leads to an increase of specific surface area external to the micropores.

Considering now the plots obtained for SD125 and SD195 after n-nonane pre-adsorption and subsequent outgassing at $50{ }^{\circ} \mathrm{C}$ and above, it is evident from Fig. 3(b) and (d) that when the outgassing temperature is increased the plots are shifted vertically and the linear sections obtained after pore filling are all parallel for each sample and start at similar values of $\alpha_{\mathrm{s}}$. Consequently, from the slopes of the second linear sections, constant values of specific area external to the micropores were obtained, namely $55 \mathrm{~m}^{2} \mathrm{~g}^{-1}$ and $69 \mathrm{~m}^{2} \mathrm{~g}^{-1}$, for SD125 and SD195. Additionally, for low $\alpha_{\mathrm{S}}$ values the linear sections do not back-extrapolate to the origin indicating primary micropore filling $[2,20]$. Therefore, it can be concluded that n-nonane was removed from ultramicropores upon outgassing at temperatures of $50{ }^{\circ} \mathrm{C}$ and above and consequently ultramicropores became accessible to nitrogen at $-196{ }^{\circ} \mathrm{C}$.

So, the intercepts of the linear sections correspond to the sum of amounts of nitrogen adsorbed in ultramicropores and supermicropores accessible to nitrogen at $-196{ }^{\circ} \mathrm{C}$ after removing $\mathrm{n}$ - 


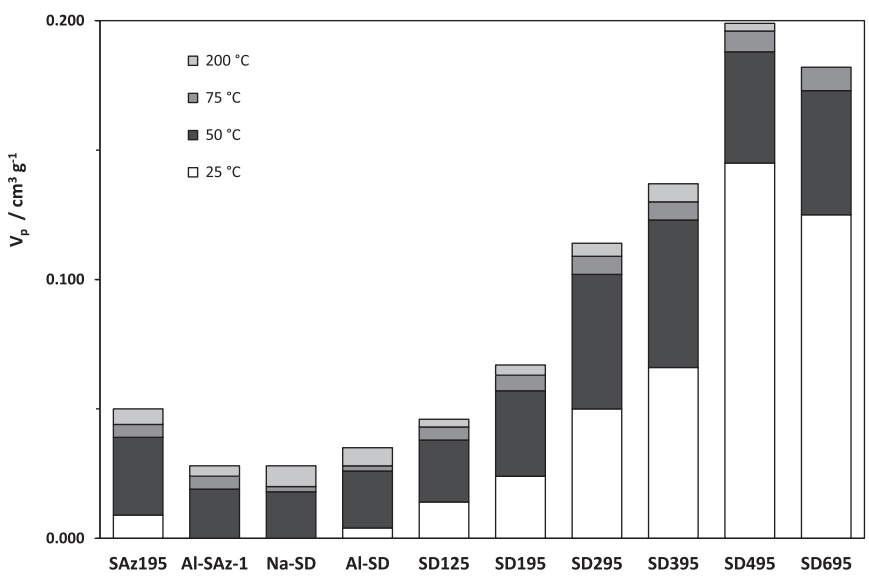

Fig. 6. Pore volumes, from which n-nonane is removed upon outgassing at increasing temperatures, obtained from the $\alpha_{S}$ plots corresponding to nitrogen adsorption, at $-196{ }^{\circ} \mathrm{C}$, on Na-SD and ion-exchanged and acid treated Na-SD and SAz-1. (The pore volumes are, in all cases, expressed per $\mathrm{g}$ of the corresponding initial material outgassed at $\left.200{ }^{\circ} \mathrm{C}\right)$.

nonane. Consequently, the volumes of ultramicropores that became available to nitrogen adsorption can be calculated, from the differences between the intercepts, and correspond to those presented in Fig. 6 for outgassing temperatures at $50{ }^{\circ} \mathrm{C}$ and above.

Some interesting aspects can be seen in a closer look of the plots of Na-SD in Fig. 3(a), upon outgassing at temperatures of $50{ }^{\circ} \mathrm{C}$ and above. The linearity extends over a long range with downward deviations to the linearity occurring at low $\alpha_{S}$ values and no linear sections that back-extrapolate to the origin in consistency with the occurrence of primary micropore filling by nitrogen. However, the long linear sections start at values at which primary and secondary micropore filling are usually complete. This feature indicates that nnonane is removed from ultramicropores and also supermicropores at $50{ }^{\circ} \mathrm{C}$ and eventually also above, which apparently seems to disagree with what was previously observed with SD125 and SD195 that n-nonane is removed from supermicropores after outgassing at $25^{\circ} \mathrm{C}$. However, the behaviour observed with Na-SD can be explained by considering that in Na-SD_C9(25) the supermicropores are blocked by n-nonane, and a plausible explanation is that the supermicropores have narrow pore entrances where nnonane stays entrapped upon outgassing at $25^{\circ} \mathrm{C}$. When n-nonane was removed by outgassing at $50^{\circ} \mathrm{C}$, the supermicropores of Na-SD became accessible to nitrogen adsorption. After micropore filling, nitrogen adsorption occurs on the external surface which corresponds to the long linear section of the plot. The specific external surface area obtained from the slope of the straight line is $55 \mathrm{~m}^{2} \mathrm{~g}^{-1}$ which is also obtained for all the other plots in Fig. 3(a) and it is equal to the BET specific surface area of Na-SD_C9(25). Consequently, Na-SD_C9(25) can be considered as a material without ultramicropores and probably also without supermicropores because n-nonane is retained in ultramicropores and is also blocking supermicropores. These results and discussion so far presented support the view that Na-SD-C9(25) is an adequate choice of reference material for the $\alpha_{S}$ plots.

So, it can be concluded that outgassing at $50{ }^{\circ} \mathrm{C}$ or above is needed to remove n-nonane from ultramicropores and very narrow entrances of supermicropores. Consequently, for SD125 and SD195 the values presented in Fig. 6 for $25{ }^{\circ} \mathrm{C}$ are volumes of supermicropores and those presented for $50{ }^{\circ} \mathrm{C}$ and above are volumes of ultramicropores. For Na-SD the values presented in Fig. 6 for $50{ }^{\circ} \mathrm{C}$ and above are volumes of ultramicropores and of supermicropores with very narrow entrances which for many practical applications can in fact be considered as ultramicropores.

It is possible that the treatments with $1 \mathrm{M} \mathrm{HCl}$ cause widening of pore entrances to the supermicropores of Na-SD which could contribute to the increase in volume of supermicropores observed in Fig. 6 for SD125 and SD195. Additionally, it can be seen in Fig. 6 that there is only a decrease in volume of very narrow micropores (values for $200^{\circ} \mathrm{C}$ ) while all the others increase indicating that, in general, the acid treatments caused appearance of new micropores and also widening of existing ones. These observations indicate similar effects of the acid treatments but more pronounced for SD195.

However, the $\alpha_{S}$ plots of SD125 show upward deviations from linearity at higher $\alpha_{S}$ values indicating condensation while for SD195 the deviations are less obvious. Moreover, for the plots of SD125 in Fig. 3(b) the average specific surface area external to the micropores calculated from the slopes is equal to that of $\mathrm{Na}-\mathrm{SD}$, while a larger value was obtained from all the plots of SD195 in Fig. 3(d). These observations indicate other effects of the acid treatments. Considering that clays are assemblages of plate-shaped particles, it is possible that macropores exist between the particles. The macropores can also account for the type of hysteresis loop [21]. The results of SD125 suggest that the treatment with $1 \mathrm{M} \mathrm{HCl}$ at $25{ }^{\circ} \mathrm{C}$ causes narrowing of voids (spaces between particles [20]) with width in the mesopore range, which could explain why there is no alteration of available specific surface area external to the micropores but onset of nitrogen condensation is seen in the $\alpha_{S}$ plots. If acid solutions attack the octahedral sheets, amorphous insoluble species may result which could explain the narrowing of voids if they remain between particles. It is expected that the dissolution of these amorphous species will be more efficient when the treatment is carried out at higher temperature and therefore less upward deviations appear in the $\alpha_{S}$ plot of SD195. Furthermore, if some stacks of layers are not strongly bound to others, it is possible that the treatment at higher temperature causes their separation. So, it can be suggested that the treatment with $1 \mathrm{M} \mathrm{HCl}$ at $95{ }^{\circ} \mathrm{C}$ may lead, in some extent, to separation of some stacks which would result in the higher specific external surface area observed for SD195.

Interestingly, the $\alpha_{S}$ plots presented in Fig. 3(c) for Al-SD present some obvious differences to those of $\mathrm{Na}-\mathrm{SD}$ and are in general qualitatively similar to those obtained with SD125. Furthermore, the specific surface area external to the micropores obtained from the slopes of all the plots of Al-SD is $55 \mathrm{~m}^{2} \mathrm{~g}^{-1}$ which is equal to the value obtained for SD125 and Na-SD from all the plots. These observations indicate that the treatments with solutions of aluminium ions and with $1 \mathrm{M} \mathrm{HCl}$ at low temperature affected $\mathrm{Na}$ SD in similar way, although to a lesser extent with the former as can be seen in Fig. 6. In fact, the results show that the treatment with solutions of aluminium ions led also to increase in supermicropore and ultramicropore volumes in comparison with Na-SD. The similarities can be, at least partially, explained by acidity resulting from the hydrolysis of aluminium ions in the ion-exchange solutions.

Although the identification of the precise location of the superand ultramicropores is outside the objectives of the current study, this aspect will be briefly addressed. Several authors have attributed differences in micropore volumes and BET areas to micropores in the edge surface resulting from imperfect stacking of layers [22-25]. Increases in BET areas and microporosity arising from the replacement of interlayer $\mathrm{Na}^{+}$ions in smectite type clays by larger cations such as $\mathrm{Cs}^{+}[22,26]$ or by divalent cations such as $\mathrm{Ca}^{2+}$ $[23,24]$ were explained by part of the interlayer space becoming partially accessible to nitrogen $[22-24,26]$. However, $\mathrm{Al}^{3+}$ ions are even smaller than $\mathrm{Na}^{+}$ions making the interlayer space too narrow for either nitrogen or $n$-nonane to access $[22,27,28]$. Therefore, the 
observed increase in micropore volume must result from other effects of the treatments. For example, if isomorphous substitution is not uniform in the clays, neither layer charge nor compensating cations will be the same in all. Furthermore, higher treatment temperature is likely to exploit the weaker interactions. It is possible that, for example, partial splitting may occur inside tactoids, leading to micropores between adjacent nearly parallel stacks (with less layers), and therefore contributing to the increase in micropore volume upon acid treatment.

\subsubsection{Porosity of $\mathrm{Na}-\mathrm{SD}$ treated with 2, 3, 4 and $6 \mathrm{M} \mathrm{HCl}$}

It is noted in Fig. 4, for SD295 and SD495 with pre-adsorbed nnonane and outgassed at $25{ }^{\circ} \mathrm{C}$, that the plots continuously increase after the first linear section, that back-extrapolates to the origin, and a second linear section can be drawn albeit at higher $\alpha_{S}$ values than those observed for the previously discussed samples. Similar features were observed for SD395 and SD695 (plots not shown). However, for SD295 and SD395, the second linear sections start at similar values close to $\alpha_{S}=1$, while for SD495 and SD695 they occur at higher $\alpha_{S}$ values. The results suggest widening of supermicropores in relation to SD195. Therefore, the plots of the samples treated with $2 \mathrm{M}$ and $3 \mathrm{M} \mathrm{HCl}$ indicate the occurrence of monomultilayer adsorption and pore filling in supermicropores, while for SD495 and SD695 the results suggest that, in addition, filling of wider pores occurs. Consequently, for samples with pre-adsorbed n-nonane and outgassed at $25{ }^{\circ} \mathrm{C}$, the pore volumes obtained correspond to supermicropores in SD295 and SD395, and also to wider pores in SD495 and SD695.

When n-nonane is gradually removed, by increasing the outgassing temperature to $50{ }^{\circ} \mathrm{C}$ and above, the plots are shifted vertically and the linear sections obtained after pore filling with nitrogen are all parallel for each sample and start at similar values. Moreover, at low $\alpha_{S}$ values the linear sections do not backextrapolate to the origin. These features are qualitatively similar to what was observed for SD125 and SD195 and therefore, as discussed previously, the volumes presented in Fig. 6 for outgassing temperatures at $50{ }^{\circ} \mathrm{C}$ and above are attributed to ultramicropores.

As seen in Fig. 6, the total volumes of ultramicropores for all these samples are higher than for SD195 and the highest value is obtained for SD395, including those that require the higher temperature to remove n-nonane. The ultramicropores are not accessible to nitrogen after $\mathrm{n}$-nonane pre-adsorption upon outgassing at $25{ }^{\circ} \mathrm{C}$ thereby indicating that n-nonane is strongly retained in ultramicropores with widths close to the minimum dimension of nonane $(0.42 \mathrm{~nm} \mathrm{[20])}$ and maybe also blocking even narrower ultramicropores. These observations suggest a more pronounced attack of the octahedral sheets generating more narrow ultramicropores within the layers. These could be partially accessible to n-nonane or blocked by n-nonane and only became available for nitrogen adsorption when n-nonane is removed.

The total volume of ultramicropores of SD495, including the very narrow ultramicropores, is smaller than that of SD395. It may be suggested that acid attack also proceeds into tetrahedral sheets resulting in widening of narrow ultramicropores. The pore volumes of supermicropores (and mesopores) is maximum for SD495, while the external surface area is maintained. These observations suggest that widening of some ultramicropores and supermicropores may have occurred.

Following acid treatment with 2,3 and $4 \mathrm{M} \mathrm{HCl}$, the mean specific surface areas external to supermicropores (and mesopores), obtained from the slopes of the straight lines drawn at high $\alpha_{S}$ values, is $55 \mathrm{~m}^{2} \mathrm{~g}^{-1}$, which is the same as the external surface area of Na-SD (equal to the BET area of Na-SD_C9(25)). The fact that the specific surface area external to the pores is maintained indicates that pores are formed inside the particles and to a higher extent as the acid concentration increases. The micropores can have formed between stacks of layers or within the stacks of layers, even within the layers.

For the sample treated with $6 \mathrm{M} \mathrm{HCl}$ more pronounced changes occurred. The specific surface area external to the pores increases to $64 \mathrm{~m}^{2} \mathrm{~g}^{-1}$ and, as Fig. 6 shows, the total specific volume of supermicropores and mesopores decreased while the volume of ultramicropores increased in spite of the disappearance of very narrow ultramicropores. The changes that occurred with $6 \mathrm{M} \mathrm{HCl}$ can be due partially to widening of some of the wider pores which then become part of the external surface.

\subsubsection{Porosity of Al-SAz-1 and $S A z 195$}

It can be seen in Fig. 5(a) that most of the plots of Al-SAz-1 are qualitatively similar to those of Al-SD but the linear section can be back extrapolated to the origin in the case of the sample with nnonane pre-adsorbed and outgassed at $25^{\circ} \mathrm{C}$ suggesting that also in this case there are no supermicropores accessible to nitrogen at $-196{ }^{\circ} \mathrm{C}$ in Al-SAz-1. However, upon increase of outgassing temperature the plots change indicating that at low relative pressures filling of super and ultramicropores by nitrogen at $-196{ }^{\circ} \mathrm{C}$ occurred. As discussed previously for Na-SD, these results indicate that Al-SAz-1 also has supermicropores with narrow micropore entrances and therefore behave as ultramicropores, although much less noticeably than for Na-SD. From Fig. 6 it can be seen that the micropore volume is similar to that of Na-SD but lower than that of $\mathrm{Al}-\mathrm{SD}$. From the slopes of the straight lines, the value of specific surface area external to the micropores obtained for Al-SAz-1 is $30 \mathrm{~m} 2 \mathrm{~g}^{-1}$, close to the BET specific surface area obtained for AlSAz-1 with n-nonane pre-adsorbed after outgassing at $25^{\circ} \mathrm{C}$, and smaller than Na-SD and Al-SD. After the linear sections all the plots display upward deviations from linearity suggesting interparticle condensation of nitrogen in the narrow voids.

The plots presented for SAz195 in Fig. 5(b) indicate differences from Al-SAz-1 which are comparable to those discussed previously between SD195 and Al-SD. In fact, in comparison to Al-SAz-1, treating SAz-1 with $1 \mathrm{M} \mathrm{HCl}$ at $95{ }^{\circ} \mathrm{C}$ led to larger volumes of micropores and also larger specific surface area external to those micropores, which is $51 \mathrm{~m}^{2} \mathrm{~g}^{-1}$ for SAz195. So, it is interesting to note that acid treatment with $1 \mathrm{M} \mathrm{HCl}$ at $95{ }^{\circ} \mathrm{C}$ increased the external surface area of both clays. However, a bigger difference in specific surface areas external to the micropores, was observed between SAz195 and Al-SAz-1 than between SD195 and Al-SD. These observations suggest that treatment with $1 \mathrm{M} \mathrm{HCl}$ at $95{ }^{\circ} \mathrm{C}$ caused more separation of stacks in the case of SAz-1 than in Na-SD.

\section{Conclusions}

n-Nonane pre-adsorption in combination with $\alpha_{S}$ plots allowed distinguishing primary from secondary micropore filling. It was possible to establish that, upon outgassing at $25^{\circ} \mathrm{C}$, n-nonane is retained in ultramicropores or is blocking ultramicropores, while it is removed from external surface, mesopores and supermicropores with entrances wider than ultramicropores. From these nitrogen adsorption data obtained with pre-adsorbed n-nonane it was possible to obtain supermicropore volumes for most of the materials. Upon outgassing at $50{ }^{\circ} \mathrm{C}$, n-nonane is partially removed from ultramicropores but all materials required outgassing at $200{ }^{\circ} \mathrm{C}$ (or $75{ }^{\circ} \mathrm{C}$ for one sample) for $\mathrm{n}$-nonane to be completely removed. However, the ultramicropore volumes were not the same for all samples after each stage of outgassing indicating differences in ultramicroporosity.

All the treatments done on Na-SD caused increase of the pore volume, while the value of specific external surface area of Na-SD was maintained for five of the seven modified samples, 
suggesting that pores were formed inside the particles and widening of micropores occurred with increasing acid concentration. Increasing the treatment temperature and the acid concentration to $3 \mathrm{M}$ caused the ultramicropore volumes and supermicropore volumes to become larger. The largest pore volume was obtained using $4 \mathrm{M} \mathrm{HCl}$ with contribution from mesopores, while the specific external surface area of $\mathrm{Na}-\mathrm{SD}$ was maintained and the volume of ultramicropores decreased slightly. When $6 \mathrm{M}$ $\mathrm{HCl}$ was used the supermicropores became wider and the narrower ultramicropores disappeared or became wider, even though the volume of ultramicropores increased in relation to SD495.

Treating Na-SD and SAz- 1 with $1 \mathrm{M} \mathrm{HCl}$ at $95{ }^{\circ} \mathrm{C}$ led to larger ultramicropore volumes, supermicropore volumes and specific external surface areas than those of Al-SD and Al-SAz-1, respectively. However, the values obtained for SD195 and Al-SD were larger than those obtained for the corresponding materials derived from SAz-1.

Hence, it is concluded that the n-nonane pre-adsorption method can be used with clays and materials derived from them. This approach allowed the amounts of nitrogen adsorbed in the ultramicropores and, for most materials in the supermicropores, to be separated from the rest of the material. Consequently, quantitative description of the ultramicropore volumes and specific external surface areas was obtained for all materials and also, for most of the materials, the volumes of supermicropores. Therefore, a detailed comparison of the porosity of ion-exchanged clays, from different origins, and after acid activation under different conditions was achieved.

\section{Acknowledgements}

This work was financially supported by Portuguese Funds through the Fundação para a Ciência e a Tecnologia (projects PTDC/ CTM-CER/121295/2010 and PEst-OE/QUI/UI0619/2013).

\section{References}

[1] S.J. Gregg, J.F. Langford, Trans. Faraday Soc. 65 (1969) 1394-1400.
[2] S.J. Gregg, K.S.W. Sing, Adsorption, Surface Area and Porosity, second ed., Academic Press, London, 1982.

[3] F. Rodríguez-Reinoso, J.M. Martín-Martínez, M. Molina-Sabio, R. Torregrosa, J. Garrido-Segovia, J. Colloid Interface Sci. 106 (1985) 315-323.

[4] P.J.M. Carrott, F.C. Drummond, M.B. Kenny, R.A. Roberts, K.S.W. Sing, Colloids Surf. 37 (1989) 1-13.

[5] A. Silvestre-Albero, M. Gonçalves, T. Itoh, K. Kaneko, M. Endo, M. Thommes, F. Rodríguez-Reinoso, J. Silvestre-Albero, Carbon 50 (2012) 66-72.

[6] O. Byl, J. Liu, J.T. Yates Jr., Carbon 44 (2006) 2039-2044.

[7] P.J.M. Carrott, F.L. Conceição, M.M.L. Ribeiro Carrott, Carbon 45 (2007) $1310-1313$.

[8] P.J.M. Carrott, L.M. Marques, M.M.L. Ribeiro Carrott, Microporous Mesoporous Mater. 131 (2010) 75-81.

[9] M. Oschatz, L. Borchardt, S. Rico-Francés, F. Rodríguez-Reinoso, S. Kaskel, J. Silvestre-Albero, Langmuir 29 (2013) 8133-8139.

[10] G.D. Parfitt, K.S.W. Sing, D. Urwin, J. Colloid Interface Sci. 53 (1975) 187-193.

[11] J.A. Lee, C.E. Newnham, J. Colloid Interface Sci. 56 (1976) 391-394.

[12] S.J. Gregg, M.M. Tayyab, J. Chem. Soc. Faraday Trans. I 74 (1978) 348-358.

[13] Y. Grillet, P.L. Llewellyn, M.B. Kenny, F. Rouquerol, J. Rouquerol, Pure App. Chem. 65 (1993) 2157-2167.

[14] Z.M. Wang, N. Yamashita, H. Kanoh, J. Colloid Interface Sci. 269 (2004) $283-289$.

[15] A. Silvestre-Albero, E.O. Jardim, E. Bruijn, V. Meynen, P. Cool, A. SepúlvedaEscribano, J. Silvestre-Albero, F. Rodríguez-Reinoso, Langmuir 25 (2009) 939-943.

[16] B. Dou, J. Li, Q. Hu, C. Ma, C. He, P. Li, Q. Hu, Z. Hao, S. Qiao, Microporous Mesoporous Mater. 133 (2010) 115-123.

[17] C. Fernandes, C. Catrinescu, P. Castilho, P.A. Russo, M.R. Carrott, C. Breen, Appl. Catal. A Gen. 318 (2007) 108-120.

[18] C. Catrinescu, C. Fernandes, P. Castilho, C. Breen, M.M.L. Ribeiro Carrott, I.P.P. Cansado, Appl. Catal. A Gen. 467 (2013) 38-46.

[19] K.S.W. Sing, D.H. Everett, R.A.W. Haul, L. Moscou, R.A. Pierotti, J. Rouquerol, T. Siemieniewska, Pure Appl. Chem. 57 (1985) 603-619.

[20] F. Rouquerol, J. Rouquerol, K.S.W. Sing, P. Llewellyn, G. Maurin, Adsorption by Powders and Porous Solids, second ed., Academic Press, London, 2014.

[21] M. Thommes, K. Kaneko, A.V. Neimark, J.P. Olivier, F. Rodriguez-Reinoso, J. Rouquerol, K.S.W. Sing, Pure Appl. Chem. 87 (2015) 1051-1069.

[22] D.W. Rutherford, C.T. Chiou, D.D. Eberl, Clays Clay Min. 45 (1997) 534-543.

[23] S. Kaufhold, R. Dohrmann, M. Klinkenberg, S. Siegesmund, K. Ufer, J. Colloid Interface Sci. 349 (2010) 275-282.

[24] S. Kaufhold, M. Plotze, M. Klinkenberg, R. Dohrmann, J. Porous Mater. 20 (2013) 191-208.

[25] M.S. Ranđelović, M.M. Purenović, B.Z. Matović, A.R. Zarubica, M.Z. Momčilović, J.M. Purenović, Microporous Mesoporous Mater. 195 (2014) 67-74.

[26] L.A.G. Aylmore, I.D. Sills, J.P. Quirk, Clays Clay Min. 18 (1970) 91-96.

[27] H. van Olphen, in: G.D. Parfitt, K.S.W. Sing (Eds.), Characterization of Powder Surfaces, Chap. 9, Academic Press, London, 1976.

[28] R.M. Barrer, Zeolites and Clay Minerals as Sorbents and Molecular Sieves, Academic Press, London, 1978. 